This is a self-archived version of an original article. This version may differ from the original in pagination and typographic details. Figures and tables are located after the references.

Please cite the original version:

Läspä, O. \& Nurmi, J. 2018. Geometrical thinning in energy wood harvesting. International Journal of Forest Engineering 29 (3), 171-178.

https://doi.org/10.1080/14942119.2018.1493845

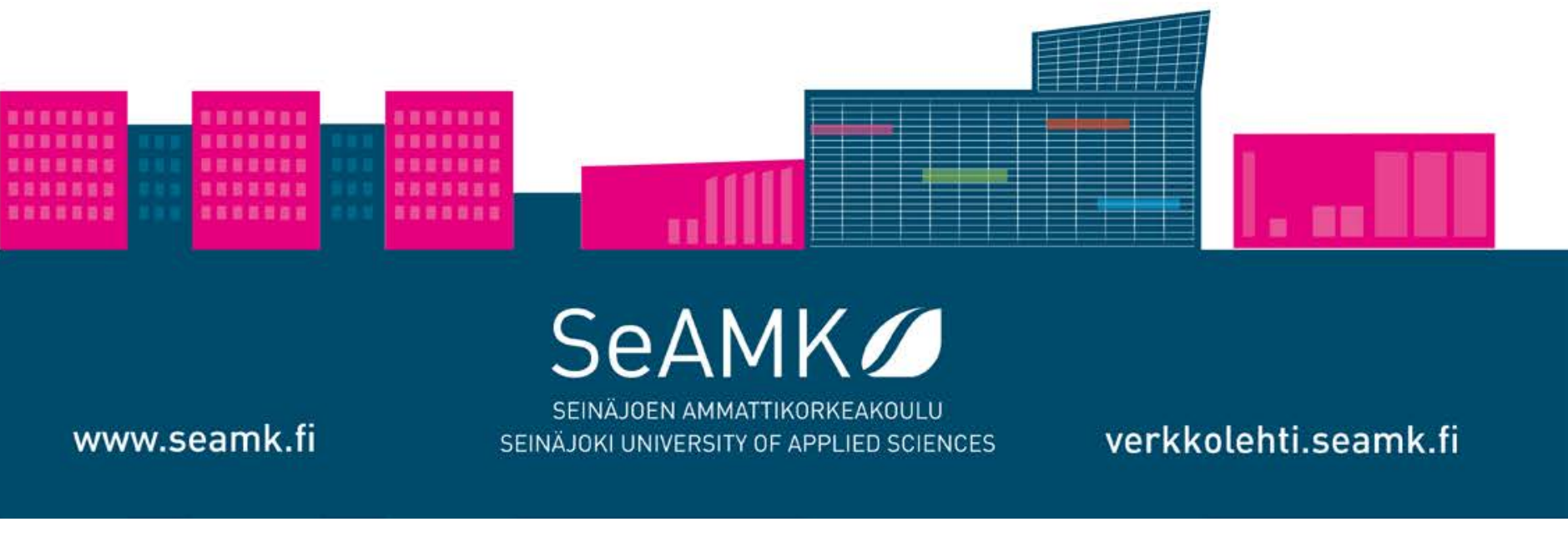




\section{Geometrical thinning in energy wood harvesting}

Läspä, $\mathrm{O}^{1}$, Nurmi, $\mathrm{J}^{2}$.

${ }^{1}$ Seinäjoki University of Applied Sciences

Kampusranta 9, Frami A, 60320 Seinäjoki, Finland

Tel. +358406807109

otto.laspa@seamk.fi

${ }^{2}$ Natural Resources Institute Finland (Luke)

Teknologiakatu 7, 67100 Kokkola, Finland

Tel. +358295323419

juha.nurmi@luke.fi

\section{Acknowledgement}

This work was supported by the EU Interreg IVA Botnia-Atlantica under Grant ID 00162639 


\title{
Geometrical thinning in energy wood harvesting
}

\begin{abstract}
Three geometrical thinning methods were tested and compared with conventional selective thinning. The geometrical harvesting methods were two boom corridor (BCT1, BCT2) and one machine corridor (MCT) methods. In BCT-methods all trees were removed from 1,5m wide and 10m deep corridors which were placed on both sides of the trip road at each operational stop. In BCT1 three corridors were made on both sides of the machine at various angles to travel direction at each operational stop at $10 \mathrm{~m}$ intervals. In BCT2 corridors were made only at 60 degree angle and 3m intervals. In MCT trees were removed only from the front of the machine.
\end{abstract}

BCT2 had the highest productivity in harvesting, forwarding and overall productivity (3.96 m3/E0). The selective thinning was even in harvesting but lower in forwarding and overall productivities (3.82 m3/E0). BCT1 productivity was lower in harvesting and forwarding with 3.68m3/E0 overall productivity. In MC the dense treetops in front of the machine often inhibited the felling and forced the harvester to reverse which reduced the overall productivity to $3.57 \mathrm{~m} 3 / \mathrm{E} 0$.

Keywords: geometrical thinning, energy wood, productivity, Scots pine

\section{Introduction}

The high procurement costs are the restricting factor in small diameter energy wood harvesting. The cost of harvesting in pre-commercial thinnings (PCT) and first thinnings (FT) by conventional techniques is strongly dependant on stem size, stand density, and to some degree removal 
(Bergström et al. 2007). Due to these high procurement costs thinnings have been neglected. The extent of PCT should be 1.6 times current volume and with FT 2.2 times the current volume in Finland (Statistical Yearbook of Forestry 2013).

In energy wood harvesting most interest has focused on multi-tree handling (MTH) with accumulating felling heads (AFH) and accumulating harvester heads (AHH). With these heads the operator can cut and collect multiple trees in the head before processing them and thus increasing productivity. Accumulating felling heads are divided into two categories, with or without a feeding capability. Feeding capability provides ability to delimb the tree with the head. Accumulating felling heads without feeding capability are lower-priced and lightweight options to applications where delimbing is not needed. Accumulating harvester heads have a feeding capability and a measuring system for precise bucking. MTH has increased productivity in other studies some 1839\%, depending on the stand density and tree size (Bergkvist 2003; Lehtimäki \& Nurmi 2011; Mäkelä et.al. 2002). Increased productivity with same harvesting cost structure means lower harvesting costs per cubic meter.

The use of MTH also enables geometric area-based thinning regimes. In conventional mechanized thinning the operator selects the trees to be thinned. In geometric area-based thinning all trees from specific areas are harvested in the one crane movement cycle and adjacent areas will stay untreated. Thus the time used on tree selection could be avoided. These geometrical areas i.e. corridors vary in width and can be divided into two main classes. They are the wider strip road like corridors driven on by the machine (Rummer 1993), and the narrower boom corridors with a width of an opened harvesting head. The wider corridors are usually parallel to the main strip roads and the boom corridors at various angles to the strip road (Bergström et al. 2007).

Geometric thinning patterns have been tested on simulations. Bergström et al. (2007) report an accumulating felling head with accumulating capability up to five trees to be $44 \%$ more productive 
with perpendicular boom corridors and 35\% more productive with fan shaped boom corridors when compared to a normal selective thinning from below. On a field study in a stand with smaller trees (average dbh of removed trees $5.7 \mathrm{~cm}$ ) Bergström et al. 2010 reported 16\% higher productivity for the boom corridor thinning when compared to normal thinning from below method.

On the other hand, Rummer (1993) reported increase of productivity with larger tree sizes. For these reasons both machine and boom corridors were tested.

In this study, three different geometrical thinning methods were tested using multi tree handling in an energy wood stand. Two boom corridor methods and one machine corridor method were chosen to compare the productivity, distribution of work time and damages to the remaining trees with normal selective thinning from below; and to analyze the total costs of harvesting chain, including harvesting and forwarding to the road side.

It was hypothesized that all geometrical thinning methods should be un-selective and more productive than the conventional selective thinning and the machine corridor method would be most suitable method for the study plots in question.

\section{Material and methods}

\section{Test site}

The test area (WGS84 co-ordinate 63.37311, 24.75453) was 4.5 hectares and located mainly on mineral soil. The stand was pine (Pinus sylvestris L.) dominated (82.9\%), of seed origin and precommercially thinned at age of 30 years. The initial number of trees/ha in the study plots varied between the plots from 1937 to 2675 trees/ha. The aim was to have stocking of 1050-1150 trees/ha after thinning. The stand was measured (DBH, height, living crown ratio, species composition) using circular sample plots with a radius of $5.64 \mathrm{~m}$ that covered $10 \%$ of the total stand area. Plot and line distance were $31.62 \mathrm{~m}$. Only trees with DBH bigger than $35 \mathrm{~mm}$ were measured. 
The stand was divided in 8 plots in northeast-southwest -orientation. Two test plots were thinned with each geometrical thinning method and two control plots with conventional selective thinning. The plots were outlined and strip roads marked. In the boom corridor method also the machine work points were marked. The plots were randomly cast between the work methods.

\section{Thinning methods}

The chosen geometrical thinning methods were based on previous simulations (Bergström et.al. 2007; Bergkvist 2003). The methods used in this study were (Fig. 1 near here):

Selective MTH-thinning from below, ST

Normal thinning of trees selected by the machine operator. Processed trees to be piled along the strip road or on the stand.

Machine corridor thinning, MCT

Trees were removed only from strip roads and two 3.5m wide parallel corridors between the strip roads. The parallel corridors were opened up and driven on by the harvester. Processed trees were piled on stand parallel to strip roads.

Boom corridor thinning 1, BCT1

Trees were removed from strip roads and from boom corridors which were $1.5 \mathrm{~m}$ wide and $10 \mathrm{~m}$ deep. Three boom corridors were placed on each side of the strip road from a single work point in such a way that one was perpendicular to the strip road, second in 45 degree angle to travel direction and third in a 135 degree angle to travel direction. Operator opened the first 4 corridors on first run along strip road. The operational limitations of the harvester forced the operator to cut the remaining 135 degree corridors once he had made a full turn at the end of the strip road and returned back. Distance between these boom corridor groups on 
strip road was 10 meters. Processed trees to be piled on boom corridors. To ease the operator work correct angles for corridors were marked on the cabin windows.

Boom corridor thinning 2, BCT2

Trees were removed from strip roads and from boom corridors. The corridors were $1.5 \mathrm{~m}$ wide and $10 \mathrm{~m}$ deep. One boom corridor was placed on each side of the strip road in 60 degree angle to travel direction. Distance between the adjacent corridors measured along the strip roads was three meters. Processed trees were piled on boom corridors. Correct angles for corridors were marked on the cabin windows.

Multi tree handling (MTH) was used in all four thinning methods. Only delimbed energy wood was produced.

\section{Field studies}

The field study was conducted in May 2011. Wood procurement was divided into harvesting and forwarding stages. Harvesting was performed with a John Deere’s 1070D -harvester with a 745 harvester head equipped for MTH. Forwarding was carried out by JD 1010 -forwarder, equipped with a crane scale. Both machines were operated by a single operator. The weighing of the harvested material was done for each plot when unloading at the road side landing.

Both harvesting and forwarding were recorded with a video camera. A time study from this video material was conducted with Ari Lauren A_aikakone time study application. The following work phases were observed in harvesting: 
1) Movement of an empty head: began when the head starts moving towards the tree and ended when sawing started.

2) Movement of a head with a tree: began when the head starts moving towards the next tree and ended when sawing started.

3) Moving the head to front of the machine: began when the head opened and felled the tree top touched the ground and ended when the harvester moved.

4) Cutting: began when sawing started and ended when head moved towards the next tree or processing started

5) Moving the felled tree: possible movement of tree or trees in the head after the cutting and before processing, began when the tree top touched the ground and ended when feeding rolls started to rotate

6) Processing: included delimbing and bucking, began when feeding rolls started to rotate and ended when the felled tree top touched the ground after sawing.

7) Driving with tree in a head: movement of the machine with a tree in the head, began when the harvester moved and ended when the movement stopped.

8) Driving: movement of the machine from one work spot to another, began when the harvester moved and ended when the movement stopped.

9) Clearing of undergrowth: clearing of undersized trees and bushes, began when the head started to close around undergrowth and ended when the undergrowth touched the ground after opening the head.

10) Moving and arranging the timber: moving of the processed timber or piles, began when the touched the timber and ended when touch broke.

11) Delay: short $1 \leq 15$ min breaks, began when all movement of the harvester ended and ended when the harvester moved again., 
12) Malfunction/Maintenance: stoppages due to the harvester, began when the engine stopped and ended when the engine stopped again.

13) Planning: planning without movements of the harvester, began when all movement of the harvester ended and ended when the harvester moved again.

The following work phases were observed in forwarding:

1) Driving with empty forwarder: began when forwarder entered the study plot and ended when it stopped at first loading spot.

2) Loading: began when the harvester stopped and crane started moving towards the timber and ended when the forwarder started moving again.

3) Arranging the grapple loads while loading: included the arrangements of grapple loads, began when the grapple load is pressed against the ground or forwarder front screen and ended when grapple closed again.

4) Arranging the load: arrangements of timber in the load space of the forwarder, began when the grapple touched timber on forwarder load space and ended when this contact broke.

5) Driving while loading: moving between the loading spots, began when the forwarder moved and ended when the movement stopped.

6) Driving with a full load: driving from last loading spot to outside of study plot, began when the forwarder moved and ended when the movement stopped.

The total time consumption in harvesting was defined by adding up the total time consumption of phases movement of an empty head, movement of a head with a tree, moving the head to front of the machine, cutting, processing, driving with tree in a head, driving, clearing of undergrowth, moving and arranging the timber, and planning. Tree specific calculations were done in these work phases. 
In forwarding summed up work phases were driving with empty forwarder, loading, arranging the grapple loads while loading, arranging the load, driving while loading and driving with a full load.

The damages were divided into stem and root damages. Stem damages were further divided into superficial damages, deep damages or broken/fallen trees. For superficial damage the tree bark had to be broken in one or more spots with a total area of exposure of $12 \mathrm{~cm}^{2}$ or more. For a deep damage the actual stem wood had to be damaged or the tree bark to have a slash or slashes with a total length over $50 \mathrm{~cm}$. For root damage, only damages that placed closer than $1 \mathrm{~m}$ from the center line of the stem were counted in (Metsäteho 2003). Roots thinner than 2cm were excluded.

\section{Mathematical methods}

The thinning methods can be divided into selective and nonselective thinnings. Selective thinnings, as the selective MTH-thinning from below (ST) in this study, have an effect on the distribution of DBH and on the mean DBH. The geometrical thinning methods (MCT, BCT1, BCT2) used in this study are supposed to be totally nonselective. This means that the distribution of DBH and mean DBH should be the same before and after the thinning in all three geometrical thinning methods (Murray \& von Gadow 1991).

In a study by Murray et al. (1991) mathematical formulas for predicting DBH changes from thinning were presented. With these equations, knowing the mean $(\mu)$, the standard deviation (o) and the variance $\left(\mathrm{o}^{2}\right)$ of the distributions (Table 1 near here) before thinning $(b)$, the thinned trees $(t)$ and the remaining trees $(r)$ the two separation parameters, that Murray calls a location separation parameter (s1) and a scale separation parameter (s2), can be calculated.

In their study Murray et al. defined the location separation parameter as 


$$
\mathrm{s}_{1}=\left(\mu_{\mathrm{r}}-\mu_{\mathrm{t}}\right) / \text { ơb }_{\mathrm{b}}
$$

And the scale separation parameter as

$$
\mathrm{S}_{2}=\left(\mathrm{or}_{\mathrm{r}}^{2-} \mathrm{O}_{\mathrm{t}}^{2}\right) / \mathrm{orb}^{2}
$$

The value that corresponds to no selectivity in both parameters is zero; $\mathrm{s}_{1}=\mathrm{s}_{2}=0$.

The location separation parameter s1 has a theoretical range of

$$
-3<s_{1}<3
$$

It achieves its maximum value when only the smallest tree (smallest DBH) is thinned. These extreme values are s1 of only possible under artificial circumstances and more realistically occur when s1 equals 1 or is slightly above it (Murrey \& von Gadow 1991).

Murray’s calculations imply that scale separation parameter s2 has a range of

$$
-1<\mathrm{s}_{2}<1
$$

The minimum value $\mathrm{s}_{2}=-1$ occurs in the degenerate case when all trees are thinned and the maximum, $\mathrm{S}_{2}=1$, when no trees are thinned.

These parameters, s1 and s2, contain all situation dependence in these equations, including the tree and stand data. This means that they can also be used to estimate if the operator has worked with the nonselective principle using only the correct corridor angles marked on windscreens ignoring his own selection when $\mu$, o and $\sigma^{2}$ are known. 


\section{Results}

\section{Distribution of $\mathrm{DBH}$}

Separation parameters for all geometrical thinning methods and the selective thinning are presented in Table 2 (near here). The parameter values for geometrical thinning methods are all close to 0 , which indicates that the non-selectivity has been quite well achieved, when natural variation in and between the real study plots is acknowledged.

\section{Distribution of the effective work time}

According to one-way analysis of variance (ANOVA) the average time consumption of harvesting work phases varied between the harvesting methods, excluding the clearing of undergrowth $(\mathrm{F}=$ 1.727 and $\mathrm{p}=0.163)$ and planning $(\mathrm{F}=2.109$ and $\mathrm{p}=0.100)$ phases (Table 3 near here).

Table 3 shows the average time consumption of a single work phases and percentage value of total effective harvester work time. The distribution of work time was quite similar between the ST, BCT1 and BCT2 methods. They all used bigger share of total work time than what MCT did in work phases prior to processing as indicated by Table 3. The ST used more time in movement of a head with a tree and moving the felled tree (avoiding the remaining trees) and cutting (harder visibility conditions due to remaining trees) phases than BCT1 and BCT2. This, however, was not statistically significant.

The MCT differed mostly from the others in the distribution of time consumption. It used significantly bigger share total work time on processing, driving with a tree in a head and driving phases. Dense treetops of trees in front of the machine inhibited often the felling and forced the harvester to reverse for more operating space. Also, the moving and arranging the timber phase was more time consuming than in other harvesting methods. 
The most significant result was time used for planning phase in both boom corridor methods. Although the correct corridor angles were marked on the machine, the operator still used a moment of time before starting the movement of an empty head phase.

In forwarding the average time consumption of work phases varied between the harvesting methods, excluding the driving with a full load $(\mathrm{F}=0664$ and $\mathrm{p}=0.604)$ phase (Table 4 near here).

The distribution of forwarder work time in table 4 did not show similar differences between harvesting methods as with harvester work time. The BCT2 used bigger share of work time for the loading phase and smaller share for arranging the grapple loads than other methods because of the parallel piles in narrow corridor entrances.

\section{Productivity}

BCT2 method had the highest productivity in harvesting $\left(6.07 \mathrm{~m}^{3} / \mathrm{E}_{0}\right)$, forwarding $\left(11.34 \mathrm{~m}^{3} / \mathrm{E}_{0}\right)$ and for the combined harvesting and forwarding chain $\left(3.96 \mathrm{~m}^{3} / \mathrm{E}_{0}\right)$. ST was practically even with BCT2 In harvesting operation but lower productivity in forwarding reduced the combined productivity by $3.4 \%$ in comparison with BCT2. BCT1 had $7 \%$ lower combined productivity than BCT2 due to lowest productivity in forwarding. MCT had lowest productivity in harvesting and in the combined chain (Table 5 near here). However, from the practical point of view the differences were small.

In table 6 (near here) is shown the mean DBH of the removed trees, the share of multi tree handling, grapple heap sizes and corridor information with each harvesting method. Due to operator selection ST method had the smallest mean DBH of removed trees. Both boom corridor thinning methods were quite similar considering these variables. They had smaller MTH percentage than ST and 
MCT methods. None of these variables shown in table 6 had any statistically significant influence to harvesting productivity according to regression analysis.

\section{Harvesting and forwarding costs}

The effective work time was converted to work time by multiplying them with a factor 1.393 for calculating the harvesting and forwarding costs. This factor between effective work time and work time is defined in Metsätehon raportti 211 (Kärhä et.al. 2009). The cost level used for these calculations were $86.6 € / \mathrm{h}$ for harvesting and $67.0 € / \mathrm{h}$ for forwarding (Laitila et.al. 2012).

The differences between methods in costs were smaller than in productivity due to different bias on harvesting and forwarding, cost rates and time consumption. BTC2 was the most cost efficient method with $2.9 \%$ margin to ST. BCT1 was 3.7\% and MCT 8.0\% more expensive when compared to ST method (Fig. 2 near here).

\section{Damages to the remaining trees}

Harvesting damages caused by ST method were all surface damages. All other methods caused also deeper damages and broken trees. ST method caused also least amount of damages (0,46 damages per harvested $\left.\mathrm{m}^{3}\right)$. BCT1 caused more $\left(0,78\right.$ damages per $\left.\mathrm{m}^{3}\right)$ damages than BCT2 $(0,66$ damages per harvested $\mathrm{m}^{3}$ ) and bigger share of deep damages and broken trees. MCT method stood out with 142,8\% (1,13 damages peharvested $\left.\mathrm{m}^{3}\right)$ in comparison with ST method. No root damages were caused by harvesting. (Fig. 3 near here). 
In forwarding (Fig. 4 near here) the BCT1 (0,071 damages per harvested $\left.\mathrm{m}^{3}\right)$ and BCT2 (0,066 damages per harvested $\mathrm{m}^{3}$ ) methods caused least number of damages . ST caused 0,103 damages per $\mathrm{m}^{3}$ and MCT again significantly more with 0,332 damages per harvested $\mathrm{m}^{3}$.

\section{Discussion}

Some caution should be used on the interpretation and generalization of the results as only one operator was used for each machine. However, it is thought that the results represent quite well the relationship of the compared methods in the given study area. Furthermore the low number of study plots encourages one to caution in interpretation of results. However, they do give a good basis for planning the further field studies and simulations.

When this study was executed in 2011, its design was based on information published prior to that date. Thus, many of the studies dealing with geometrical thinning were not available at the time. Furthermore, as many of the studies on geometrical harvesting have concentrated on denser stands with smaller tree sizes (Bergström 2009, Bergström et. al. 2010, Bergström et.al. 2012), it was considered justifiable to apply geometrical methods on Scots pine stands for two reasons. First, the pine dominated stands which are most common in Finland and Sweden lack behind in active management work and a new harvesting technique could be part of the solution. Second, concentrating studies of an alternative harvesting approach only on dense, often hardwood dominated coppiced stands would keep both scientific and industrial communities unaware of the possible applicability of corridor techniques in coniferous stands.

The hypothesis of this study, based on previous studies and simulations, was that all geometrical thinning methods should be more productive than the conventional selective thinning. Furthermore, 
the MCT method should be most suitable method for the test sites in question due the average size and density of trees. The results indicate that this did not come true except for BCT2 method which was most productive in both harvesting and forwarding.

The stand conditions were actually least suitable for the MCT which was contrary to the hypothesis. Dense treetops of big trees in front of the machine often inhibited the felling and forced the harvester to reverse for more operating space which was not expected. This equals to significantly bigger share of total work time in processing, driving with a tree in a head and driving phases. Also, the moving and arranging the timber phase was more time consuming because of the narrow unharvested strips beside the strip road that caused difficulties for placing the processed trees along the corridors. This means that MCT was not the most suitable method for these stand conditions. Also, both boom corridor methods would probably have benefitted from a denser stand as reported by Bergström et al. (2010). Average number of trees harvested from one corridor was only 2.5 with BCT1 and 2.2 with BCT2.

In BCT1 the corridors pointing backwards in 135 degree angle could not be harvested during the same pass with other corridors due to inadequate stability of the harvester with full length boom reach. This increased time spent on driving and thus decreased the productivity of harvesting with this method. In BTC1 the logs were often crossed at beginnings of the corridors. This increased time used for arranging the grapple loads while loading. Both of these problems were factors that were not anticipated based on simulations (Bergström et al. 2007, Sängstuvall et al. 2012) Apparently the operator's unfamiliarity of the working methods BCT1 and BCT2 methods required the biggest share of effective working time on the planning phase (BCT1 4.3\% and BCT2 4.2\%). This was despite the assisting measures of clearly marked corridor angles on the harvester windscreen. If the time used for planning in these two methods could have been completely removed, as suggested by Bergström et.al. (2007), the productivity difference with the ST method 
have changed to a more positive one from $0.2 \%$ to $4.4 \%$ with BCT2 and from $-2.7 \%$ to $1.6 \%$ with BCT1.

Bergström (2009) found in his study that boom corridor method significantly reduced the time consumption for the work element Crane in-between which was roughly comparable to Movement of a head with a tree work phase in study. Similar effect was found also in this study, time share for this work phase decreased from 16.8\% (ST) to 11.7\% (BCT1) and 11.8\% (MCT). For some reason BCT2 had higher time share, $14.0 \%$.

In spite of the differences between harvesting methods the geometrical methods provided means for non-selective thinning according to the calculative analysis suggested by Murray et.al. (1991). This confirmed the expectations based on previous study by Bergström et.al. (2007). The result also minimizes the critical factor of using just one harvester operator.

The lowest occurrence of damages in conventional thinning indicate operator's experience in it. The boom corridor methods performed also well and especially in forwading the neat log piles in corridor openings of BCT2 method functioned well. The MCT suffered from the lack of working space both in harvesting and forwarding. In this case felling the trees down against standing trees caused lot of superficial damages and in forwarding the parallel log piles between remaining trees next to a striproad caused lot of extra maneuvering and thus damages.

The main result of this study was that appropriate geometrical thinning pattern increased the harvesting and especially forwarding productivity, although not as much as one might have expected according to simulations (Bergström et al. 2007). The operator was able achieve the nonselectivity well in all geometrical thinning methods but not to overcome the time used for planning. According to simulations, this work phase should not have existed at all. 
In conclusion, according to these results the most productive combination with conventional AHH and AFH could be a denser stand and boom corridor harvesting with one or two corridors to both sides from each stopping point. The corridors should be in $<90$ degree angle to the travel direction and the processed trees in parallel piles. This alternative wood procurement combined to operator training should result in improved wood procurement efficiency. The next step towards higher productivity in FT and especially in PCT could be new heads capable of continuous felling and accumulation. In pure felling study these have already proven effective (Bergström et al. 2012).

\section{References}

Bergkvist, I. 2003. Flerträdshantering höjer prestationen och ökar nettot i klen gallring. Skogforsk. Uppsala. Resultat. (5). p.1-4.

Bergstrom, D., Bergsten, U., Nordfjell, T. \& Lundmark, T. 2007. Simulation of geometric thinning systems and their time requirements for young forests. Silva Fennica 41. p. 138145.

Bergström, D. 2009. Techniques and systems for boom-corridor thinning in young dense forests. Acta 6 Universatis Agriculturae Sueciae, Doctoral thesis no. 2009:87.

Bergstrom, D., Bergsten, U. \& Nordfjell, T. 2010. Comparison of boom-corridor thinning and thinning from below harvesting methods in young dense scots pine stands. Silva Fennica 44(4) p.669-679.

Bergstrom, D., Bergsten, U., Hörnlund, T. \& Nordfjell, T. 2012. Contionuous felling of small diameter trees in boom corridors with a prototype felling head, Scandinavian Journal of Forest Research, 27:5. p. 474-480. 
Sängstuvall, L., Bergström, D., Lämås, T., \& Nordfjell, T. 2012. Simulation of harvester productivity in selective and boom-corridor thinning of young forest. Scandinavian Journal of Forest Research, 27:1. p. 56-73.

Kärhä, K., Laitila, J., Jylhä, P., Nuutinen, Y. \& Keskinen, S. 2009. Kokopuun paalaus tuotantoketjun tuottavuus ja kustannukset. Metsätehon raportti, 211, 61. p. 22.

Laitila, J., Väätäinen, K. \& Asikainen, A. 2012. Kanto- ja juuripuun nosto hakkuutyön yhteydessä turvemaalla. Metlan työraportteja / Working Papers of the Finnish Forest Research Institute 248. 23 s. p. 13.

Lehtimäki, J. \& Nurmi, J. 2011. Energy wood harvesting productivity of three harvesting methods in first thinning of scots pine (Pinus sylvestris). Biomass and Bioenergy. 35(8). 3383-3388. p. 4.

Metsäteho. 2003. Korjuujälki harvennushakkuussa (http://www.metsateho.fi/wpcontent/uploads/2015/03/Korjuujalki_harvennushakkuussa_opas.pdf) p. 17.Murray, D. M. \& Von Gadow, K. 1991. Relationships between the diameter distributions before and after thinning. Forest science. 37(2). 552-559. p. 2-5.

Mäkelä, M., Poikela, A. \& Liikkanen, R. 2002. Joukkohakkuu aines- ja energiapuun korjuussa. Metsäteho Report. 137. 1-18. p. 11.

Rummer, R.P. 1993.Thinning with the Gafner Tri-Trac feller/buncher: a case study. Research paper of the Southern Forest Experiment Station. USDA Forest Service. (SO273):5. p. 1-4.

Statistical Yearbook of Forestry 2013

(http://www.metla.fi/julkaisut/metsatilastollinenvsk/index-en.htm). p. 103-146. 


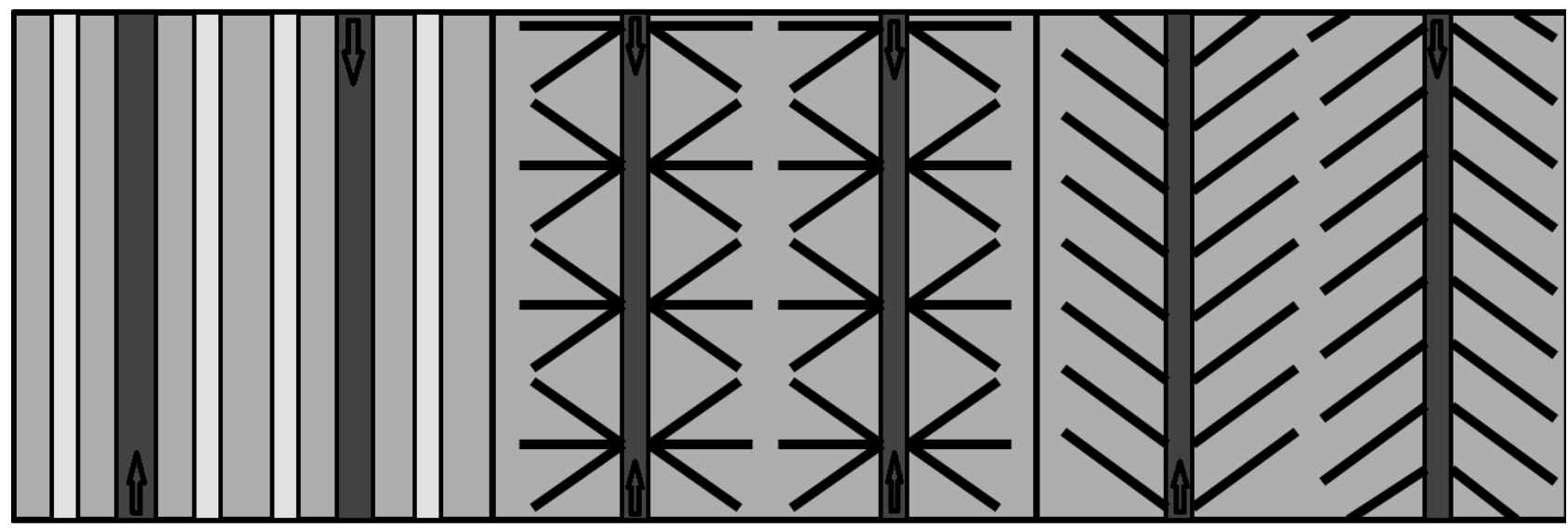

Fig 1. Patterns of geometrical thinning methods. Driving directions on the strip roads marked with black arrows. 


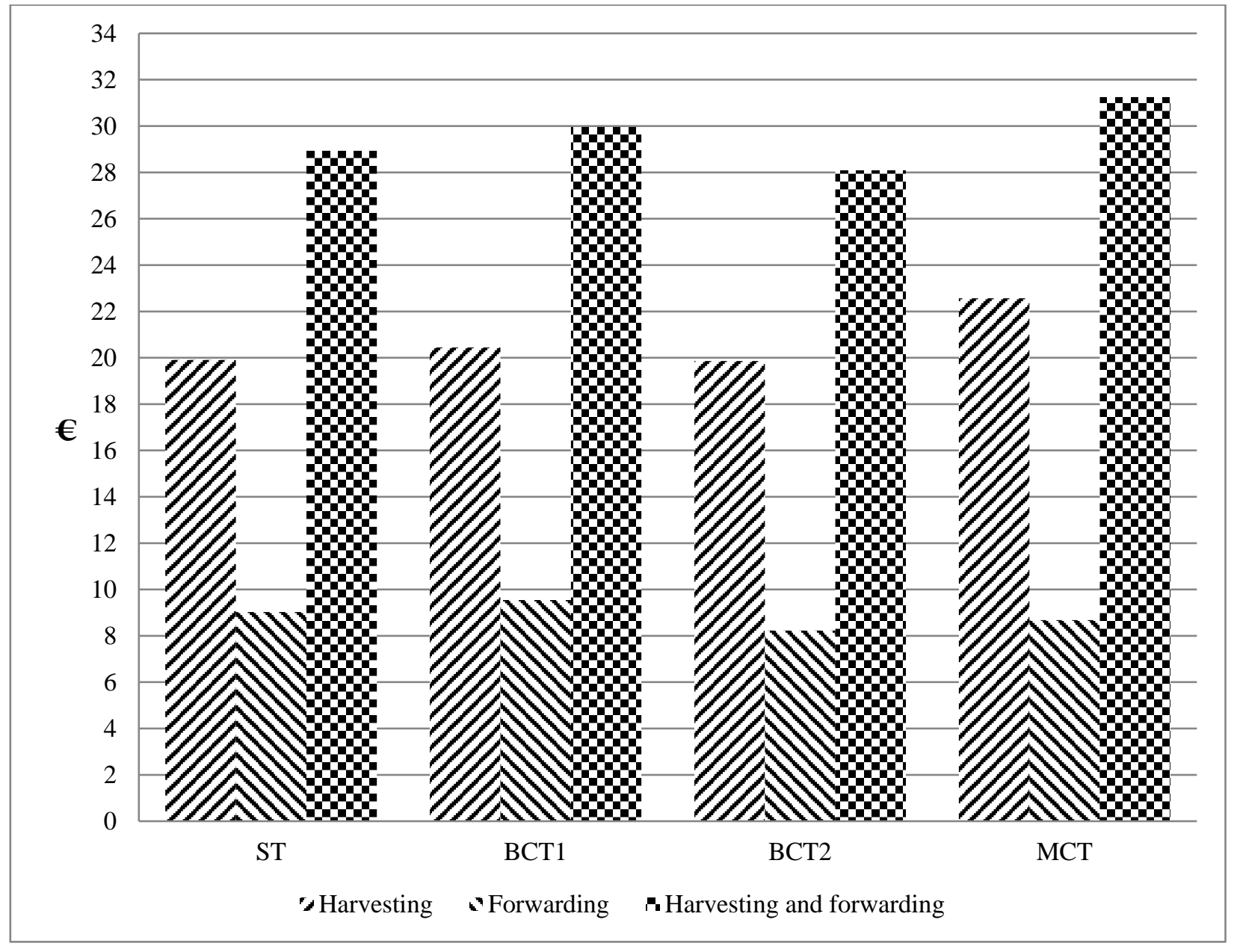

Fig 2. Harvesting costs $€ / \mathrm{m} 3$ 


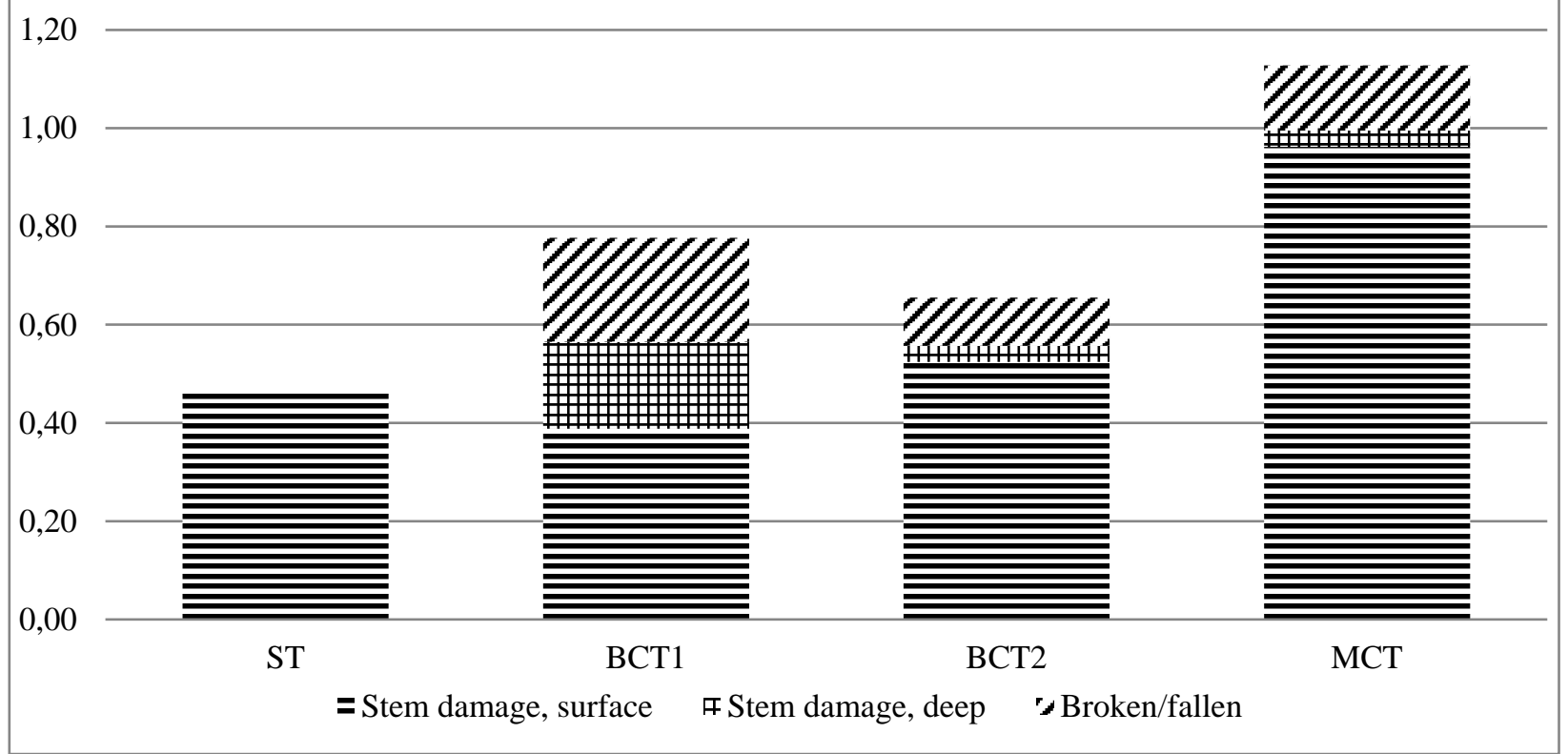

Fig 3. Damage per m3 caused by harvesting. 


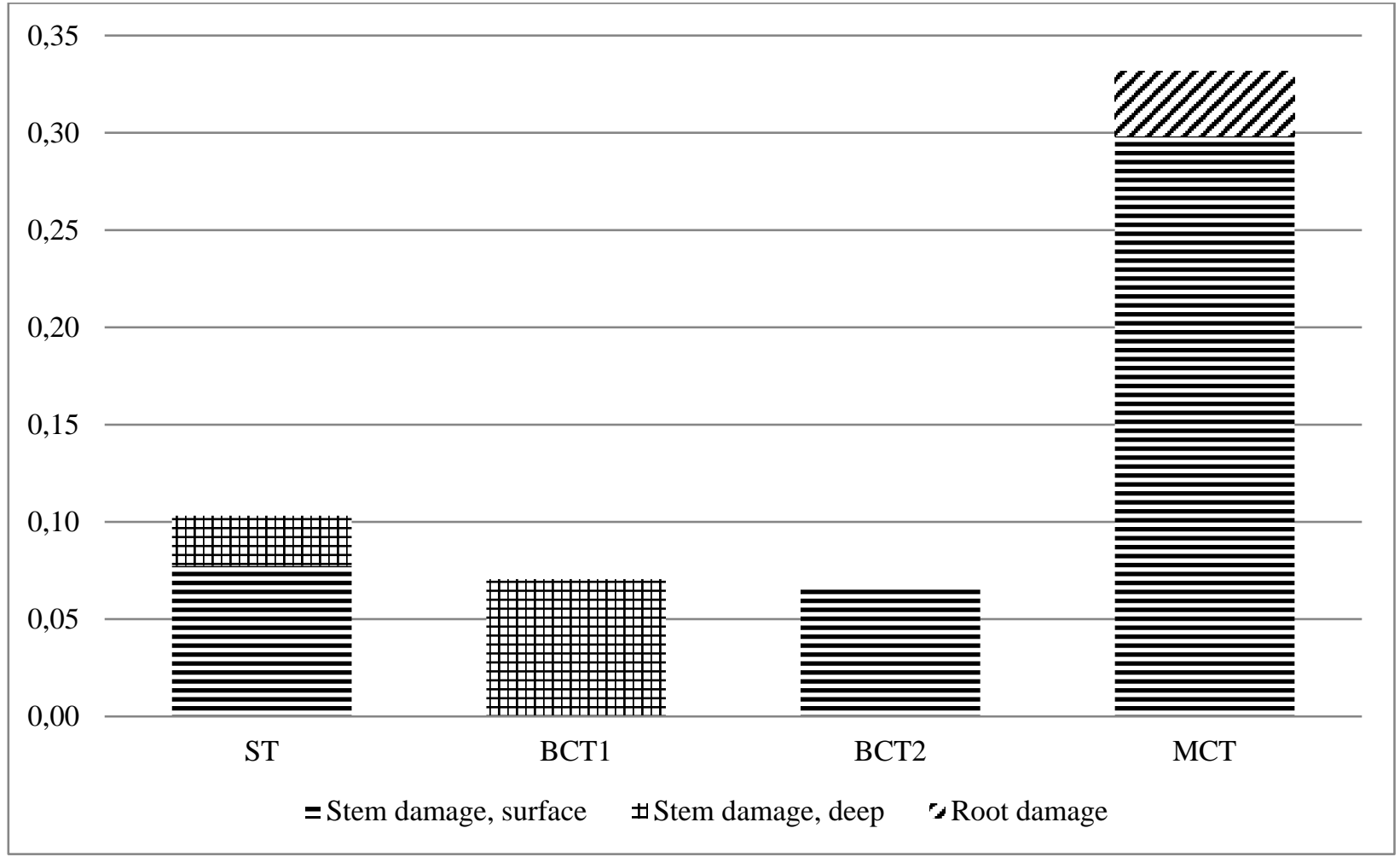

Fig 4. Damage per m3 caused by forwarding. 
Table 1. Percentage distribution of diameter at breast height before and after the thinning with means and variances.

\begin{tabular}{cccccc} 
Diameter at breast height & Before thinning & ST & BCT1 & BCT2 & MCT \\
\hline \hline $35-60 \mathrm{~mm}$ & 20.8 & 4.3 & 21.8 & 23.8 & 11.4 \\
$61-90 \mathrm{~mm}$ & 29.0 & 16.2 & 30.5 & 24.3 & 32.0 \\
$91-120 \mathrm{~mm}$ & 29.2 & 43.3 & 24.2 & 30.1 & 34.2 \\
$121-150 \mathrm{~mm}$ & 14.4 & 30.1 & 13.8 & 16.5 & 13.9 \\
$151-180 \mathrm{~mm}$ & 4.3 & 6.0 & 4.8 & 4.5 & 6.0 \\
$181-\quad \mathrm{mm}$ & 2.3 & 0.0 & 4.8 & 0.9 & 2.5 \\
\hline & & & & \\
\hline \hline Mean (mm) & 90.3 & 106.7 & 94.7 & 90.0 & 99.2 \\
Variance & 1297.2 & 878.5 & 1455.0 & 1296.2 & 1290.2 \\
Std dev. & 36.0 & 29.6 & 38.1 & 36.0 & 35.9 \\
\hline Removal & & & & \\
\hline Mean (mm) & & 82.5 & 90.2 & 94.0 & 92.9 \\
Variance & & 709.7 & 1329.5 & 1279.2 & 1439.3 \\
Std dev. & 26.6 & 36.5 & 35.8 & 37.9 \\
\hline \hline
\end{tabular}


Table 2. The location and the scale separation parameters for the thinning methods

Thinning method

\begin{tabular}{llcccc}
\cline { 3 - 5 } Separation parameters & & ST & BCT1 & BCT2 & MCT \\
\hline \hline Location separation & S1 & 0,671 & 0,125 & $-0,113$ & 0,175 \\
Scale separation & S2 & 0,130 & 0,097 & 0,013 & $-0,115$ \\
\hline
\end{tabular}


Table 3. Average time consumption and timeshare of thinning methods according to harvesting work phases. Statistical results for work phases of one-way analysis of variance.

\begin{tabular}{|c|c|c|c|c|c|c|c|c|c|c|c|}
\hline \multirow[b]{2}{*}{ Work phases } & \multicolumn{8}{|c|}{ Thinning method } & & \multirow[b]{2}{*}{$\mathbf{F}$} & \multirow[b]{2}{*}{$\mathbf{p}$} \\
\hline & ST & BCT1 & ВСТ2 & MCT & ST & BCT1 & ВСТ2 & MCT & & & \\
\hline & $\stackrel{\underline{s}}{\text { mean }}$ & $\stackrel{\underline{s}}{\text { mean }}$ & $\stackrel{\underline{s}}{\text { mean }}$ & $\stackrel{\underline{s}}{\text { mean }}$ & $\%$ & $\%$ & $\%$ & $\%$ & $\begin{array}{l}\% \\
\text { mean }\end{array}$ & & \\
\hline Movement of an empty head & 5,2 & 5,9 & 5,9 & 5,0 & 15,5 & 16,3 & 16,1 & 11,0 & 14,7 & 10,538 & 000 \\
\hline Movement of a head with a tree & 5,2 & 5,3 & 6,4 & 5,6 & 16,8 & 11,7 & 14,0 & 11,8 & 13,6 & 17,060 & 000 \\
\hline Moving the head to front & 3,7 & 4,6 & 5,4 & 3,9 & 6,0 & 8,1 & 9,7 & 1,8 & 6,4 & 65,919 & ,000 \\
\hline Cutting & 1,8 & 1,7 & 1,8 & 1,7 & 10,7 & 7,9 & 8,4 & 7,4 & 8,6 & 3,222 & 022 \\
\hline Moving the felled tree & 4,3 & 4,1 & 4,4 & 3,9 & 12,4 & 10,3 & 11,2 & 6,8 & 10,2 & 22,891 & ,000 \\
\hline Processing & 7,7 & 8,4 & 8,6 & 14,9 & 22,2 & 21,4 & 21,8 & 32,0 & 24,4 & 140,843 & 000 \\
\hline Driving with tree in a head & 5,5 & 6,8 & 7,6 & 10,2 & 3,0 & 2,9 & 2,5 & 6,9 & 3,9 & 19,612 & , 000 \\
\hline Driving & 7,1 & 13,9 & 9,5 & 12,9 & 9,5 & 14,6 & 9,9 & 17,1 & 12,8 & 37,828 & 000 \\
\hline Clearing of undergrowth & 9,2 & 7,8 & 7,2 & 6,7 & 2,1 & 1,9 & 1,7 & 1,6 & 1,8 & 1,727 & 163 \\
\hline $\begin{array}{l}\text { Moving and arranging the } \\
\text { timber }\end{array}$ & 11,9 & 8,8 & 10,5 & 19,2 & 1,2 & 0,6 & 0,4 & 2,8 & 1,2 & 3,933 & ,012 \\
\hline Planning & 5,8 & 5,9 & 6,7 & 8,1 & 0,6 & 4,3 & 4,2 & 0,8 & 2,5 & 2,109 & 100 \\
\hline Total & 67,3 & 73,3 & 74,0 & 92,2 & 100,0 & 100,0 & 100,0 & 100,0 & & & \\
\hline
\end{tabular}


Table 4. Average time consumption and timeshare of thinning methods according to forwarding work phases. Statistical results for work phases of one-way analysis of variance.

\begin{tabular}{|c|c|c|c|c|c|c|c|c|c|c|c|}
\hline Work phases & ST & BCT1 & ВCT2 & MCT & ST & BCT1 & BCT2 & MCT & & $\mathbf{F}$ & $\mathbf{p}$ \\
\hline & $\stackrel{\underline{\mathbf{s}}}{\text { mean }}$ & $\stackrel{\underline{\mathbf{S}}}{\text { mean }}$ & $\stackrel{\underline{\mathbf{S}}}{\text { mean }}$ & $\stackrel{\underline{\mathbf{s}}}{\text { mean }}$ & $\%$ & $\%$ & $\%$ & $\%$ & $\begin{array}{c}\% \\
\text { mean } \\
\end{array}$ & & \\
\hline Driving with empty forwarder & 0 & 9.3 & 10.1 & 0 & 0 & 0.4 & 0.5 & 0 & 0.2 & & \\
\hline Loading & 14.8 & 14.2 & 14.3 & 16.4 & 48.1 & 46.7 & 55.6 & 48.2 & 49.7 & 7.220 & .000 \\
\hline Arranging the grapple loads while loading & 12.3 & 13.2 & 8.3 & 11.7 & 16.7 & 17.4 & 12.6 & 13.8 & 15.1 & 8.577 & .000 \\
\hline Driving with a full load & 4.2 & 22.9 & 7.0 & 3.1 & 0.1 & 0.9 & 0.2 & 0.1 & 0.3 & .664 & .604 \\
\hline Driving while loading & 11.7 & 11.0 & 9.7 & 12.6 & 14.2 & 12.5 & 13.2 & 14.4 & 13.6 & 3.448 & .017 \\
\hline Arranging the load & 12.1 & 12.5 & 10.5 & 15.2 & 21.0 & 22.0 & 17.9 & 23.5 & 21.1 & 5.300 & .001 \\
\hline Total & 55.1 & 83.0 & 59.8 & 58.9 & 100 & 100 & 100 & 100 & & & \\
\hline
\end{tabular}


Table 5. Productivity of harvesting, forwarding and for the whole harvesting chain for each thinning method.

Thinning method

\begin{tabular}{lcccc|ccccc}
\cline { 2 - 9 } Productivity & ST & BCT1 & BCT2 & MCT & ST & BCT1 & BCT2 & MCT \\
\hline \hline & $\mathrm{m}^{3} / \mathrm{h}_{\mathrm{E}}$ & $\mathrm{m}^{3} / \mathrm{h}_{\mathrm{E}}$ & $\mathrm{m}^{3} / \mathrm{h}_{\mathrm{E}}$ & $\mathrm{m}^{3} / \mathrm{h}_{\mathrm{E}}$ & $\%$ & $\%$ & $\%$ & $\%$ \\
\cline { 2 - 9 } Harvesting & 6,06 & 5,90 & 6,07 & 5,35 & 100,0 & $\mathbf{9 7 , 4}$ & 100,2 & 88,2 \\
Forwarding & 10,34 & 9,78 & 11,34 & 10,75 & 100,0 & 94,6 & 109,7 & 104,0 \\
Combined productivity & 3,82 & 3,68 & 3,96 & 3,57 & 100,0 & 96,3 & 103,5 & 93,4 \\
\hline
\end{tabular}


Table 6. Mean DBH of the removed trees, share of multi tree handling, grapple load sizes and corridor data.

\begin{tabular}{ccccccc} 
& DBH $_{\text {R }}$ & MTH-\% & $\begin{array}{c}\text { Trees/grapple } \\
\text { heap }\end{array}$ & $\begin{array}{c}\text { Crane } \\
\text { cycles/corridor }\end{array}$ & $\begin{array}{c}\text { Harvested } \\
\text { trees/corridor }\end{array}$ & $\begin{array}{c}\text { Empty } \\
\text { corridors \% }\end{array}$ \\
\hline \hline ST & 82.5 & 62.5 & 2.7 & & & \\
BCT1 & 90.2 & 53.5 & 2.5 & 1.5 & 2.5 & 11.7 \\
BCT2 & 94.0 & 54.1 & 2.5 & 1.5 & 2.2 & 16.7 \\
MCT & 92.9 & 66.3 & 2.6 & & & \\
\hline
\end{tabular}

